\title{
Cross-border Entrepreneurial Education, Development and Knowledge and Technology Transfer: Experiences with the Cambridge-Riga Venture Camp Programme-A Reflective Report
}

Journal of Entrepreneurship and Innovation in Emerging Economies $7($ I) 99-105, 2021

(C) The Author(s) 2021 Reprints and permissions: in.sagepub.com/journals-permissions-india DOI: I0.I I77/2393957520984035 journals.sagepub.com/home/eie

(9SAGE

\section{Alan Barrell', Anders Paalzow ${ }^{2}$, Elmars Baltins ${ }^{3}$, Jan Storgårds ${ }^{4}$, Karlis Purmalis ${ }^{5}$, Kristine Berzina ${ }^{5}$, Madara Mara Irbe ${ }^{6}$ and Modris Ozolins 6}

\begin{abstract}
Over a 6-year period, a collaboration has been developed between a group in Cambridge, UK, and two Latvian Universities, Stockholm School of Economics in Riga and other organisations, including Riga City Council, supported by the British Embassy Riga and the Latvian Embassy in London, enabling structured processes to be developed to identify aspiring entrepreneurs based in Latvia and Estonia and provide education, coaching, mentoring and encouragement first in the home territory, leading to an intense whole-week development venture camp in Cambridge for selected candidates. The programme was extended to provide ongoing business development support for a number of entrepreneurial companies with global potential, and the developing venture camp activities attracted, supported and helped accelerate the evolution in Riga of an innovative ecosystem providing leadership in the Baltics. Practical examples of cross-border knowledge and technology transfers have been recorded as part of the Cambridge-Riga Venture Camp process. This report presents the development, content and outcomes of this innovative project aimed at supporting the emergence of entrepreneurial and innovative capabilities of Latvian delegates to the project. Detailed appendices including data and narrative based survey of outcomes and assessments containing structured feedback from delegates
\end{abstract}

\footnotetext{
'Cambridge Worldwide Associates, Micklen House, Cambridge, UK.

${ }^{2}$ Stockholm School of Economics in Riga, Riga, Latvia.

${ }^{3}$ CONNECT Latvia, Riga, Latvia.

${ }^{4}$ Anglia Ruskin University, Cambridge, Cambridgeshire, UK.

${ }^{5}$ University of Latvia, Riga, Latvia.

${ }^{6}$ Riga Technical University, Riga, Latvia.
}

\section{Corresponding author:}

Alan Barrell, Cambridge Worldwide Associates, Micklen House, 19 Sedley Taylor Rod, Cambridge, CB2 8PW, UK.

E-mail: alan@alanbarrell.com 
participating in the 2020 Cambridge-Riga Venture Camp are available as the Supplementary material online. This is an interim report, since the activity is ongoing and continuously developing.

\section{Comments by Anders Paalzow-As an Independent Assessor-Rector, Stockholm School of Economics, Riga and Chairman Connect Latvia}

What started in 2014 as an initiative between a group in Cambridge, UK, and the non-profit association Connect Latvia, with the aim of bringing to Latvian entrepreneurs an opportunity to expand their perspectives through going to Cambridge, has now developed into a programme involving three Latvian institutions of higher education, the Riga City Council, the Latvian Embassy in UK and the British Embassy in Latvia, and several other partners. Today's programme is organised in two steps, with an overall aim of enabling structured processes to be developed to identify aspiring entrepreneurs based in Latvia and Estonia. The first takes place in Riga and provides education, coaching, mentoring and encouragement. The second step, open to selected candidates, comprises an intense venture camp week in Cambridge. The programme has been extended to ongoing business support for a number of entrepreneurial companies with global potential, and the developing venture camp activities have attracted, supported and helped accelerate the evolution in Riga of an innovative ecosystem providing leadership in the Baltics. Furthermore, practical examples of cross-border knowledge and technology transfers have been recorded as part of the Cambridge-Riga Venture Camp process. This article concludes with a data- and narrative-based survey of outcomes and assessments containing structured feedback from participants in the 2020 Venture Camp. Finally, this could be seen as an interim report, since the venture camp is continuously developing.

The report includes post-activity reflections from Professor Alan Barrell, seeking to draw lessons for all and pointers for future activities based on the experiences and results.

\section{Origins and Beginnings}

\section{The Cambridge Phenomenon}

During a period commencing in the 1960s and continuing to the present day, Cambridge has been the centre of extraordinary innovative development based around a centre of scientific and technological excellence and expertise supported by growing capabilities in the commercialisation of research and the establishment of a fast-growing 'cluster of creativity' within which, at the time of writing, there exist 4,700 knowledge-based companies and more than 60,000 'Hi-Tech' jobs. Eighteen companies born in Cambridge during this period have assumed a value in excess of US\$1 billion. Two have exceeded US $\$ 10$ billion and one US\$25 billion. Very significant inward investment has occurred-both through large global corporates bringing research and money and through UK-based and inbound venture capital and private equity investment. In 2019, the Cambridge economy recorded a 9\% growth — at a time when the UK overall managed $0.1 \%$. The so-called 'Cambridge Phenomenon' has been seen to emerge as a result of the accumulation of particular capability in new business start-ups and scale-ups-largely in the technology sector. The existence of this innovative and entrepreneurial ecosystem has attracted significant numbers of executives and aspiring entrepreneurs, including undergraduates and graduates, to visit Cambridge for short courses related to innovation and entrepreneurial business development. From the year 2000 onwards, a number of entrepreneurial short courses have been organised by Cambridge 
University's Judge Business School and by independent organisations and groups. The annual entrepreneur programme at Judge Business School, Ignite, has become an exemplar in its field, and international organisations, such as GYDO (Global Youth Development Organisation) founded in Beijing and bringing many Chinese undergraduate entrepreneurs to Cambridge and the CFCC (China Future Creative Class) company based in Shenyang Liaoning Province, have been active in involving hundreds of visiting entrepreneurial students.

\section{The Latvian Interest}

The concept of the 'venture camp', an intensive, often-transformational course to get entrepreneurs quickly equipped to grow companies already started or give birth to new ones, has become a flexible and variable process enabling numerous successful business developments. It was in 2013-2014 that Elmars Baltins, Director of Connect Latvia, attended one of the GYDO Chinese undergraduate venture camps directed by Professor Alan Barrell and raised the question 'Why not Cambridge-Latvia Venture Camps?' 'Why not?' was adopted as a positive motto as Professor Barrell and Elmars Baltins made the first plans to explore venture camps in Cambridge preceded by local activities and some entrepreneur training, development and preparation in Latvia and Estonia.

\section{Reflections (i): What We Have Learned}

From a standing start in 2013, we have observed that whilst technology transfer is much discussed and we have good experience of it, not much is observed about 'experience transfer' or 'transfer of inspiration'. These were important elements in the Cambridge-Latvian programme. Delegates gained enormously from experience and mindset transfer. We also learned that in such developing countries as Latvia, there is not simply a latent pool of entrepreneurial talent and almost certainly as many innovative ideas as found in any square mile or metre in other centres, but there is an extra dimension of enthusiasm and unreleased energy if the means to develop and exploit ideas are suppressed. This meant that the levels of attention and dedication to use the offered education, mentoring and opportunities were exceptional. By the end of the programmes, our classes were brimming with energy, excitement, anticipation of next steps and expectations of progress. We also learned anew the importance of 'the mentor'. Real mentors take a deep interest in their mentees, and this showed through. Skilled mentorship is something to be developed and nurtured. One conclusion we reached was that perhaps there should be more structured programmes to develop mentors, enabling mentoring skills to be better understood and developed. We also learned that for a group of highly motivated Latvian entrepreneurs, exposure to a full week in the Cambridge entrepreneurial environment was, for some, life-changing. They told us so. Human interaction embraces knowledge, emotion, values, anxieties, connectedness, connectivity and character development, which is impossible to measure but which is vitally important to the personal development of people.

\section{Development of the Programme}

From 2014 onwards, Professor Barrell and a small number of Cambridge-based colleagues began visits to Riga and other locations in Latvia and Estonia with support from Connect Latvia and Elmars Baltins, Stockholm School of Economics in Riga, Riga Technical University and University of Latvia, running workshops to find and encourage entrepreneurs and, to begin with first steps of preparation and training 
in the home base, establishing the means to identify and qualify those entrepreneurs eventually invited to attend an intense 1-week programme as a conclusion of the venture camp. The process quickly became an annual event, with growing numbers of entrepreneurs seeking engagement each year. In 2019, there were 104 applicant entrepreneurs to the Riga programme, and 50 were accepted to the Riga module; eventually, 39, including several faculty members as mentors, attended the final intense 1-week venture camp in Cambridge in January 2020.

One of the catalysts to start the international entrepreneurial exchange programme for Baltic entrepreneurs in Cambridge was an initiative of the Swedish Embassy in Riga and the Swedish Institute in the period 2014-2017, when they funded through Connect Latvia several regional entrepreneurship courses in Latvia and Estonia, especially in the non-capital cities. During that period, courses were run in Daugavpils, Rezekne, Liepaja and Valka in Latvia and Kohtla-Jarve and Valga in Estonia. These local programmes confirmed that the spirited and passionate young entrepreneurs in the Baltics were ready for the international journey.

The progression and development of the programme was made possible through not only the determination of the small group of founders, faculty of teachers, coaches and mentors but also through the progressive engagement of many more partners, who each play a key role in the programme and have a specific purpose, including Anglia Ruskin University, Cambridge campus, the Ambassador and Deputy Head of Mission at the Embassy of Latvia in London and Latvian Investment and Development Agency, the British Embassy in Riga, companies, innovation centres and science parks in Cambridge and the YHA Cambridge hostel management.

Initially, the programme was truly 'bootstrapped'. Basic expenses were covered by Connect Latvia and Latvian universities, and all involved in planning, organisation, teaching and mentoring contributed time and materials pro bono. The first 4 years of the programme proceeded on this basis. In the second year, Blue Orange bank and public financial institution Altum made the first modest commercial and public contributions to the programme. In due course, Riga City Council became an active participant in the programme's organisation and provided financial support, which enabled teachers to be paid modestly for work undertaken in the 2019-2020 programme and also enabled more international travel. Throughout the programme, entrepreneurs/delegates have contributed to the strictly developed costs of the programme. In the last 3 years, Anglia Ruskin University has made available excellent teaching accommodation and use of all facilities without charge. There have been donations of teaching materials, including appropriate books. The teaching faculty have become increasingly closely aligned and bonded to enable the development and delivery of an integrated and coherent programme of teaching, visits and events. Successful entrepreneurs have been supported beyond the venture camp through ongoing coaching and mentoring and introductions to investors and prospective clients internationally. Case studies will be subject to the writing up of practical experiences.

\section{Reflections (ii): What We Have Learned}

'In the beginning there was the word' - not to place a too-Biblical connotation on the situation, but the point to be made is that the environment and support structures for entrepreneurial development when the programme began were minimal at best. Latvia had progressed since the dissolution of the Soviet Union, but mindsets and attitudes were of a very mixed nature. The gap between the next generation now enjoying greater freedom and the large 'elder groups' was significant. Western approaches to marketing and free-spirited thinking were at early stages of adoption. Universities and institutions - and city councils - were in varying states of transition. Economic development had been struggling. Educational 
standards were however high. The leading universities were strong in research. Talent was obvious and developing fast in the areas of new opportunity, such as information technology (IT) and bioscience. Ingredients for progress in the commercialisation of knowledge and research were in place. Processes of innovation were lacking, and support for entrepreneurial education was 'neonatal'. Financial support for entrepreneurial education and finance for high-risk new-business formation was not much in evidence. Although technical talents were developing, outside investment to enable many innovative companies to get going was lacking. The Cambridge-Latvia Venture Camp activity was initially a relatively closed activity with support from inspired individuals at Riga Technical University and University of Latvia, Connect Latvia and the Swedish Institute. The role of Stockholm School of Economics in Riga was crucial in providing a physical home for early activities. We learned that our evangelism took effect only after we were able to demonstrate practical results from the efforts expended. We learned that promotion through professional activities and diplomatic and university connections were great ways to market our activities and display our successes. Support gathered once we could show the model worked and enabled more new companies to start and grow, from sponsors and from governments, including an increasing engagement of the Riga City Council, which is now an integral partner in the programmenot just a funder. Financial institutions are coming in. Our university partners have become very active and engaged. In the UK, Anglia Ruskin University is a partner in all senses of the word. We have learned that in Cambridge there is a population of entrepreneurs willing to devote time and energy to support the development of entrepreneurs and ecosystems beyond the shores of the UK-not for commercial gain but through a belief that extending the entrepreneurial network of influence brings benefits home and abroad. We also learned how important diplomatic sources of support through ambassadors and embassies can be. We learned that patience and perseverance can pay off if consideration is given to "what all parties have to gain from an activity'. We have learned that there are rarely shortcuts to the kinds of relationships between parties engaged in this kind of activity need to agree upon to establish an enduring activity and continuity of purpose and performance.

\section{Some Results and Outcomes of the Five Years of Activity}

During the course of the 5 active years of the programme, at least 500 entrepreneurs in Latvia/Estonia and other territories have become involved. More than 100 entrepreneurs have proceeded to complete the Cambridge intense week of the programme. Tracking of the post-event progress of participants has not been undertaken due to lack of resources. However, a number of companies starting life at the venture camp or joining it soon after formation can be cited as examples of successful progress and, in some cases, international success and recognition. As stated, work to record and publish case study examples is proceeding. During the period of the 6 years' work on Cambridge-Riga Venture Camps, we have witnessed significant developments in the functional innovation ecosystem in Riga, with increased investment in university engagement and investment in entrepreneurial education, technology transfer and the commercialisation of research. In the light of the European Union co-funded investments made in university facilities, innovation infrastructure and education in entrepreneurship in Latvia and Estonia, the Cambridge-Riga Venture Camp could be seen as a way of further leveraging these investments. Riga City Council has been actively involved in the encouragement and support of new-business formation and entrepreneurs. Incubators and accelerators have been financed and staffed with enthusiastic management. Established businesses and the investment community have worked together in support of early stage company development. International connections have been opened and expanded. It can be claimed, as some suggest, that Riga has become 'The Innovation Centre of the Baltics'. Riga is an 
international centre with its own impressive science-and-technology base and now connected globally, with Cambridge having become a significant channel of inward and outbound innovation and knowledge exchange.

Through the work of a Cambridge group, Connect Latvia, universities and Riga City Council, the first results of limited post-activity research surveys can be published as part of this report. See Appendices 1-6 for more details of the programme layout and the results of the survey work recently undertaken following the 2019-2020 programme.

Finally, it has to be noted that the programme also involves significant learning about cultural life and diplomatic relationships, which is part of the development of an entrepreneur. Professor Alan Barrel recited a new rhyme during the formal dinner of the fifth programme at the historic Madingley Hall in Cambridgeshire on 31 January 2020 - 'A 2020 RIGA-CAMBRIDGE RHYME':

We join together across borders - our simple plan — to save the world,

Entrepreneurs with marching orders - flags of friendship are unfurled.

Our passion is to start things new-and make our world a better place,

From dreams and visions - companies grew - to enter in the business race.

We will depart with sadness stained - to make it home and knuckle down,

To use all the new knowledge gained - and grow our business all year round.

We are the Latvia-Cambridge crowd - hands across borders is our theme,

We proudly shout our message loud-We are the years true winning team!

\section{Reflections (iii): What We Have Learned}

With due modesty, we have learned that perseverance and keeping in mind a clear vision of what is intended, and patience with a small and modest beginning, can pay off. Without claiming too much credit, we would say we have learned that the beginnings of the development of new entrepreneurial ecosystems can be demonstrated through the results achieved in 6 years' activity in Latvia — principally in Riga. We have learned that it is not feasible or even rational to take the view that 'we will create a Cambridge or Silicon Valley in Latvia' - if that was suggested. However, we have learned that lessons learned in Cambridge and observations on how the entrepreneurial ecosystem developed there can provide pointers for how successful developments can be supported elsewhere but based on the inherent strengths of the new location. Strengths can be built upon. We would not claim our programme alone is responsible for the dramatic developments in the entrepreneurial ecosystem in Riga in the past 10 years. However, we would point out that when we began there were no incubators or science parks in Latvia, nor did university education focus on entrepreneurship and innovation. Further, we would point out that there was very little national, regional or municipal engagement in these areas. We have learned how engagements develop over time with those institutions and organisations able to invest in and support entrepreneurial developments through patient 'proving of principals'. We needed willing volunteers on the ground in Latvia and Estonia, as well as wonderful and willing believers and supporters in Cambridge to teach, coach and mentor, and we did enjoy increasing support from universities in Latvia and the UK. The dedication of specific individuals - some named as authors of this report-was critical. Connect Latvia was pivotal.

Today, the Riga entrepreneurial ecosystem is established and will endure. There are three new business accelerators, more incubators and a growing cluster of technology companies. Latvia is rich in talent, especially in IT and now artificial intelligence - and in bioscience. We see pathways from knowledge and technological excellence to products in markets. Translational processes are in place. We predict a 
bright entrepreneurial future. We do not claim our Cambridge-Latvia Venture Camp has achieved it all, but we do believe the efforts have made a significant contribution. It is an example of 'bottom-up' evolution - mostly driven by a number of ordinary citizens in centres inspired with a single-minded purpose to 'make things happen'.

\section{Supplemental Material}

Supplemental material for this article is available online. 